\title{
O lugar do "nada" no horizonte da crítica heideggeriana à noção de ciência tradicional
}

\author{
The place of nothing in Heidegger critical horizon the traditional science \\ notion
}

\author{
BRUNO JOSÉ DO NASCIMENTO OLIVEIRA ${ }^{1}$
}

\begin{abstract}
Resumo: O presente trabalho tem o objetivo de explicitar a crítica do filósofo alemão Martin Heidegger à ciência tradicional que, ao longo do tempo, ignora a questão do nada como um aspecto negativo na busca pela descoberta cientifica. Tal investigação se empenha em responder o problema do nada, como sendo a questão fundamental do ser, pois é dessa análise que Heidegger compreende o desabrochar do ser do ente, como um fenômeno essencialmente humano. Assim, temos o objetivo primordial de indicar a crítica que o filósofo constrói à ciência quando estas se ocupam dos acontecimentos históricos e naturais do ser e do mundo. Para compreender esta dinâmica, vamos trabalhar os conceitos de ente, ser e nada na tentativa de pensar como estes se estruturam no cotidiano do saber cientifico e existencial.
\end{abstract}

Palavras-chave: Heidegger. Ciência. Nada.

Abstract: The present work has the purpose of explaining the criticism of the German philosopher Martin Heidegger to traditional science, which over time ignores the question of nothing as a negative aspect in the search for scientific discovery. Such a research endeavors to answer the problem of nothingness as the fundamental question of being, for it is from this analysis that Heidegger understands the unfolding of the being of being as an essentially human phenomenon. Thus, we have the primary objective of indicating the criticism that the philosopher constructs science when they are concerned with the historical and natural events of being and of the world. To understand this dynamic, we will work on the concepts of being, being and nothingness. In an attempt to think how these are structured in the everyday of scientific and existential knowledge.

Keywords: Heidegger. Science. Anything.

\section{Introdução}

O texto de Martin Heidegger: O que é metafísica? teve como um dos principais objetivos analisar o fenômeno do nada como sendo o foco principal para responder à questão do sentido do ser. No entanto, ao longo do tempo foi ignorada pela ciência, ou seja, a ciência tradicional ao investigar aquilo que se propõe, desconsidera possível qualquer questão sobre o nada, ou até mesmo rejeita considerar a questão do nada como fundamento para suas conjecturas.

\section{A crítica à ciência e o ente}

\footnotetext{
${ }^{1}$ Mestrando em Filosofia pela Universidade Federal do Piauí na linha de pesquisa de linguagem, conhecimento e mundo. Bolsista da Fundação de Amparo à Pesquisa do Estado do Piauí (FAPEPI)
} 
Na primeira parte de sua preleção, Heidegger já nos adverte de que a pergunta posta pelo título de seu escrito, $O$ que é metafísica? não será tema central em sua discussão, pois, para falar da metafísica, se faz necessário "mergulhar" na própria metafísica. Sendo assim, nos situaremos do melhor lugar para falarmos da metafísica, ou seja, dentro dela mesma.

Para Heidegger, a questão metafísica abarca a totalidade de toda metafísica, ou seja, é de interesse do filósofo ao investigar a metafísica em si mesma. Trata-se de responder a questão metafísica pelo sentido do ser, enquadrando-a como o único problema a ser encarado, antes de iniciar toda investigação cientifica. Em contraposição a isso, as universidades fragmentam o conhecimento, dificultando a investigação sobre a metafísica, pois a ciência é "[...] apenas mantida numa unidade pela organização técnica de universidades e faculdades e conserva um significado pela fixação das finalidades práticas das especialidades" (HEIDEGGER, 1983, p. 35).

Em vista disso, a organização das ciências se dá através de componentes curriculares comuns, ou seja, apenas em razão de sua finalidade, eliminando então o aprofundamento da ciência como uma unidade sistêmica que corresponde a totalidade das questões do mundo e do ser. O enraizamento das ciências é de extrema importância para o saber científico, mas que desapareceu completamente por meio da subdivisão das ciências por áreas de interesses.

Para Heidegger, existem três dimensões fundamentais para a compreensão da totalidade abarcada pela metafísica - referência ao mundo, comportamento e irrupção. Ora, segundo o filósofo, essas três dimensões revelam a unidade simples do Dasein:

Se quisermos apoderar-nos expressamente da existência científica, assim esclarecida, então devemos dizer: Aquilo para onde se dirige a referência ao mundo é o próprio ente - e nada mais. Aquilo de onde todo o comportamento recebe sua orientação é o próprio ente e além dele nada. Aquilo com que a discussão investigadora acontece na irrupção é o próprio ente e além dele nada (HEIDEGGER, 1983, p. 36).

Desse modo, a ciência sempre pautou suas pesquisas pelo seu direcionamento ao ente, mas Heidegger encontra, na própria busca científica, o problema por ela encarado, quer dizer, a busca pelo ente é própria do saber científico que deixa escapar o elemento que nadifica o ente, ou seja, o nada. E nesse intento pelo elemento nadificador do ente, Heidegger distingue o que se chama de ente. $O$ ente é, para o filósofo, aquilo que corresponde ao ôntico, isto é, o ente é o elemento que se relaciona com o ser, através de uma "relação" imbricada que se refere ao Dasein, logo, ao ontológico. Portanto, ente e ser estão em relação ôntica e ontológica no que diz respeito ao ente e o ser, onde o nada terá um papel fulcral na busca pela verdade do ser. 


\section{O nada que nadifica e acende a clareira do ser}

O comportamento e referência ao mundo pela ciência é direcionado apenas ao ente, e nada mais. Pois bem, é esse nada que Heidegger nos advertiu de que pensar sobre o nada, constitui um novo redirecionamento para a ciência. Como ele próprio atesta: "o nada é justamente rejeitado pela ciência e abandonado como elemento nadificamente" (Heidegger, 1983, p. 36). O que Heidegger pretende com essa afirmação é apontar o erro da ciência tradicional e, ao mesmo tempo, mensurar ao redor de sua crítica a reformulação do problema para a ciência.

Na elaboração da questão sobre o nada que está no interior da metafísica, Heidegger indica que é possível problematizar o nada e apontar onde reside o problema dentro da metafísica e nas próprias questões elencadas pela ciência, pois, para o filósofo, toda hipótese feita pela ciência tradicional tem como finalidade o ente, rejeitando assim o nada:

A ciência nada quer saber do nada. Mas não é menos certo que também que, justamente ali, onde ela procura expressar sua própria essência, ela recorre ao nada. Aquilo que ela rejeita, ela leva em consideração. Que essência ambivalente é essa? (HEIDEGGER, 1983, p. 36).

A dicotomia diagnosticada por Heidegger diz respeito à rejeição do nada pela ciência, pois, ao rejeitá-lo como elemento basilar em seus métodos e hipóteses, o cientista comete o erro de não começar pelo fundamento a fim de investigar a coisa ela mesma. É que ao partir suas considerações do ente, a ciência parte da coisa já existente e concreta. Sendo assim, o encontro da verdade do ente e do ser é comprometido pela não consideração do nada, que uma vez considerado, envolve o ente em sua negação, sendo possível ir de encontro ao que fundamenta o ente e consequentemente pelo fundamento ontológico do ser.

Ainda sobre o nada, nos diz Heidegger: "o nada é a negação da totalidade do ente, o absolutamente não ente” (HEIDEGGER, 1983, p. 37). Heidegger encontra na negação a problematização do nada, invertendo e indo contra todos os princípios da lógica formal, ou seja, se algo é somente aquilo que é, pelo princípio da identidade, como falar de algo que não é, ou que nega a si próprio?

Heidegger recorre à negação para explicitar algo extremamente recorrente em sua filosofia, a negação de conceitos. Quer dizer, Heidegger se reapropria do conceito de verdade para os gregos, como Alétheia sendo essa, como se sabe, a verdade originária como desvelamento da verdade. Trata-se, portanto, de desencobrir o Dasein pelo movimento de desvelamento e velamento do ser. Heidegger usa o conceito de não ente para extrair a essência do ente e, por conseguinte, do nada, uma vez que o não ente e não nada, pode nadificar o mundo aberto das remissões. 
Heidegger volta a observar que a totalidade do ente não é algo que é facilmente apreendido, mas se "o nada é a plena totalidade do ente" (HEIDEGGER, 1983, p. 38) o homem se encontra no meio dessa totalidade, imerso e alocado dentro da rede remissiva que vela e desvela o ser do ente. A partir disso temos que perguntar, onde podemos encontrar o ente em sua totalidade? Heidegger responde: "A totalidade do ente deve ser previamente dada para que possa ser submetida enquanto tal à negação, na qual, então, o próprio nada se devera manifestar" (HEIDEGGER, 1983, p. 38).

A questão do nada está posta. O nada é aquilo que deve se manifestar junto com o ente em sua totalidade, logo a manifestação do nada por meio do ente ocorre através de uma "totalidade unitária" da qual o ente é uno e primordial. No diz Heidegger:

Tão certo como é que nós nunca podemos compreender a totalidade do ente em si e absolutamente, tão evidente é, contudo, que nos encontramos postados em meio ao ente de algum modo desvelado em sua totalidade. E está fora de dúvida que subsiste uma diferença essencial entre o compreender a totalidade do ente em si e o encontrar-se em meio ao ente em sua totalidade. Aquilo é fundamentalmente impossível. Isto, no entanto, acontece constantemente em nossa existência (HEIDEGGER, 1983, p. 38).

Ora, a compreensão da totalidade do ente se torna impossível segundo Heidegger. Porém, a nossa existência e as coisas que estão ao nosso alcance são compreendidas pelo encontrar-se em meio ao ente, isto é, em sua totalidade, mas a compreensão da totalidade dos entes e o alcance dos objetos por suas disposições constituem duas formas de compreensão e experiência da totalidade do ser. Eles fazem parte de uma unidade da qual nos é revelada apenas a parte que se abre para por meio do desvelamento do mundo. A coisa em si, ou a totalidade do ente em seu ser ôntico é inacessível para nós entes mundanos.

Para o autor alemão, a preocupação do nada faz parte da vida cotidiana do serai, mas a tradição, propende a não considerar o nada. Fato é que tendemos a não pensar a questão como uma possibilidade para encontrar o sentido do ser. Mas é impossível fugir dessa questão, uma vez que, na vida cotidiana, estamos em contato com outros Dasein (Dasein) além de seres intramundanos, ou seja, com seres que nos vem ao encontro dentro do mundo, já que o nada, ser e ente fazem parte de uma totalidade unitária.

É dai que ocorre a transformação do Dasein em angústia. A sensação de nadificação revela a angústia do homem na totalidade, "o nada se revela na angústia" (HEIDEGGER, 1983, p. 40). O sentido de angústia que Heidegger pretende abordar, não diz respeito ao sentido de vazio existencial muitas vezes elencada pelo 
existencialismo. Diferentemente disso, o sentido de angústia que Heidegger menciona é angústia como encaminhamento para a questão do nada.

A angústia nos retira da existência tranquila, uma vez que nós enquanto seres mundanos somos acomodados, pois sempre imaginamos possuir o conhecimento seguro e concreto. A manifestação da angústia, como encaminhamento para a questão do nada, surge da noção de que quando pensamos o nada, esse nada sempre diz respeito a algo, e não há um vazio sem sentido. Assim, quando a angústia passa, diz se costumeiramente: "propriamente não foi nada" (HEIDEGGER, 2015, p. 253). O existencialismo ao se referir a angústia traduz o sentimento de angústia por meio de sua relação com os seres intramundanos. Ora, para Heidegger, tal relação não é cabível, pois a angústia se angustia consigo mesma.

O nada que nos abstemos de pensar constitui algo mais originário que os seres intramundanos geralmente investigados de forma errônea pela ciência tradicional. A questão é que o ser no mundo se angustia com ele mesmo, ou seja, a angústia não é apreensão do nada, mas é manifestação do nada na totalidade. Esse nada, porém, está imbricado em relação ao ente. Ambos não se distinguem um do outro, mas o nada pode ser pensado como um impulso ou manifestação própria do nada.

Desse modo, Heidegger diz sobre a totalidade em que o nada se manifesta por meio da angústia. A angústia está em lugar nenhum. O lugar nenhum não diz respeito a nenhum aspecto negativo, e sim parte do Dasein do próprio ser. A partir da afirmação do autor: "O próprio nada nadifica" (HEIDEGGER, 1983, p. 40) vemos a importância do nada para Heidegger, sugerindo que é através do nadificar que o ente se revela como abertura para o mundo.

A tranquilidade em que o Dasein se encontrava é perdida através da noção de nada. Ora, o aspecto metafísico que a noção de nada implica visa justamente a noção tradicional de ser e ente: "A essência do nada originalmente nadificante consiste em: conduzir primeiramente o Dasein diante do ente enquanto tal" (HEIDEGGER, 1983, p. 41). O papel do nada é conduzir o ser para o caminho da autenticidade do pensamento, enquanto possibilidade de ser, mediante uma abertura como projeto de pensamento a ser realizado.

O próprio sentido de Dasein surpreende o leitor no texto O que é metafisica? Heidegger conceitua o Dasein como: "estar suspenso dentro do nada" (HEIDEGGER, 1983, p. 41). A busca pelo sentido do ser, perpassa a maioria dos escritos de Heidegger. Pois bem, é nessa busca que ele entende a suspensão do Dasein diante do nada. O filósofo compreende tal relação a partir de uma visão unitária do mundo. É por meio precisamente da transcendência que o autor diz ser possível o nada se relacionar com o ente e consigo próprio.

A questão metafísica do nada envolve a totalidade metafísica que, por sua vez, envolve o mundo e, consequentemente, a questão científica marcada pelo seu apego 
ao ente, que funda a ciência como a conhecemos. Heidegger se apropria da questão metafísica, pois, nos escreve ele:

Nossa interrogação pelo nada tem por meta apresentar-nos a própria metafísica. O nome "metafísica" vem do grego: tà metá physika. Está surpreendente expressão foi mais tarde interpretada como caracterização da interrogação que vai metá - trans "além" do ente enquanto tal (HEIDEGGER, 1983, p. 42).

Heidegger se utiliza dessa transcendência para inserir a questão do nada como uma questão essencialmente metafísica. Afinal, a questão transcendente do nada escapa a todos os moldes lógicos e científicos até então conhecidos. A metafísica nesse sentido está além do ente. Esse não é determinado por nenhum conhecimento absoluto ou acabado. O ente é antes algo do próprio homem que deve ser investigado, pois a questão do nada coexiste ao Dasein, ou seja, a natureza humana é formada por uma totalidade inerente a seu ser.

Em vista disso, levando em consideração o projeto da ontologia fundamental empreitado por Heidegger é notório que o filósofo buscou compreender o sentido do ser, ou o Dasein de forma específica, o que, a princípio, sugere um rompimento de Heidegger com a ciência tradicional. Ora, no entanto, tal rompimento representa apenas um distanciamento do que a modernidade compreende por ciência, pois o autor alemão encara a ciência como metafísica em contraposição ao positivismo do período contemporâneo.

A ciência, para Heidegger, não deve possuir apenas caráter teórico, mas deve ser também prática, no sentido de pensar o ente a partir de si mesmo, interrogando os fundamentos de suas próprias questões, em sentido ontológico, pois somente dessa maneira a ciência pode ser levada a sério:

Com o cumprimento dessas tarefas encontramo-nos na encruzilhada em que se decide se iremos tocar a essência da ciência ou se essa está irremediavelmente perdida - e isso de tal modo que essa perda ainda continue trazendo consigo a aparência de verdade (HEIDEGGER, 2009, p. 47).

A ciência para obter valor de conhecimento e verdade não pode prescindir da necessidade de que ela encare todas as formas possíveis de pensamento. Ou seja, trata-se de pensar o nada como ponto de partida fulcral para o desenvolvimento de qualquer elaboração de hipótese, ou qualquer tentativa de compreender a ontogênese do Dasein no mundo.

É nesse sentido que Heidegger constrói sua opinião crítica a respeito das ciências tradicionais, ou aos moldes de fazer ciência que estamos habituados nas universidades. A preocupação de Heidegger diz respeito à maneira que as ciências lidam não só a questão do nada, como uma possibilidade de ser, mas da forma que 
elas abordam o Dasein, abstendo-se de encarar o ente, como uma forma fixa e determinada.

Para o filosofo alemão, a metafísica deve acompanhar a ciência, por isso, o nada é um problema metafísico, ou seja, deve corroborar com a ciência em seus métodos de pesquisas, pois:

\begin{abstract}
Somente porque o nada está manifesto nas raízes do Dasein pode sobrevir-nos a absoluta estranheza do ente. Somente quando a estranheza do ente nos acossa, desperta e atrai ele a admiração. Somente baseado na admiração - quer dizer, fundado na revelação do nada - surge o porquê. Somente porque é possível o porquê enquanto tal, podemos nós perguntar, de maneira determinada, pelas razões e fundamentar. Somente porque podemos perguntar e fundamentar foi entregue à nossa existência o destino do pesquisador (HEIDEGGER, 1983, p. 44).
\end{abstract}

\title{
Conclusão
}

Apesar da crítica que Heidegger à ciência, ele não pretende através do avanço da metafísica superar a ciência tradicional, mas desdobrar a ciência para uma preocupação diferente da tradição. Trata-se da preocupação do esquecimento do ser, recolocando a pergunta pelo sentido do ser. Isso, para o filósofo, a princípio é uma das questões cientificas mais difíceis e das mais importantes a serem resolvidas, pois o problema do ser e do ente revela a questão fundamental ontológica, ou seja, a compreensão do Dasein

Através disso, Heidegger se tornou um importante pensador das ciências humanas, principalmente, na filosofia.

\section{Referências}

HEIDEGGER, M. Que é metafísica? Trad. Ernildo Stein. São Paulo: Abril Cultural, 1983. . Introdução à filosofia. Tradução de Marco Antonio Casanova. São Paulo: Martins Fontes, 2009.

. Ser e tempo. Trad. Márcia Sá Cavalcanti. Petrópolis, RJ: Vozes, 2015.

Submissão: 12.02.2019 / Aceite: 15.05.2019. 